\title{
In-Beam Stress Corrosion Tests for Welded 308 Stainless Steel in Pure Water at $473 \mathrm{~K}$
}

\author{
Yoshiharu Murase*, Norikazu Yamamoto, Tadashi Shinohara, \\ Akira Tahara, Toshiho Ogata and Kazuhiro Kimura \\ National Institute for Materials Science, Tsukuba 305-0047, Japan
}

Stress corrosion tests were performed for welded 308 stainless steel under proton irradiation at $473 \mathrm{~K}$. The concentration of oxygen and hydrogen in the feed water was controlled to be below 5 and $10 \mathrm{ppb}$, respectively. The in-beam loading condition was 0 and $300 \mathrm{MPa}$ in tension under an irradiation dose rate of $1.3 \times 10^{-7} \mathrm{dpa} / \mathrm{s}$. The electrochemical corrosion potential (ECP) was also measured during the tests. After the corrosion tests, the specimen surface at the fusion zone was examined by SEM for all specimens. Extensive electrochemical reactions on the specimen surface were implied by ECP measurement under the in-beam loading condition. The initiation of surface cracking followed by coalescence of numerous larger corrosion pits at the boundaries of ferrite phases in the austenitic matrix was detected for the in-beam specimens at $300 \mathrm{MPa}$. Thus, the initial process of stress corrosion cracking at weld metal would be accelerated under irradiation.

[doi:10.2320/matertrans.MAW201411]

(Received April 17, 2014; Accepted June 9, 2014; Published July 18, 2014)

Keywords: welded stainless steel, stress corrosion cracking, fusion zone, proton irradiation, corrosion pit, in-beam stress corrosion test

\section{Introduction}

Austenitic stainless steels have been widely used as structural materials in high-temperature water environments because they have excellent corrosion resistance due to the formation of a passive film on their surfaces. However, in some simultaneous conditions of water chemistry, external/ internal stresses and microstructural features of materials, localized corrosive attacks on the passive film can lead to the initiation of stress corrosion cracking (SCC). In particular, welding processes are often responsible for the enhanced susceptibility to SCC due to the introduction of metallurgical changes and residual stresses to materials. ${ }^{1,2)}$ The welded joint is a heterogeneous material consisting of the base metal, the weld metal and the heat-affected zone. Among these zones, the weld metal of austenitic stainless steel has been designed to have a cast structure with ferrite phases in the austenite matrix in order to prevent hot-cracking during weld metal solidification. ${ }^{3,4)}$ In exchange for this merit, preferential formation of corrosion pits at the boundaries of ferrite phases $^{5,6)}$ and the initiation of SCC along the boundaries ${ }^{7,8)}$ have been pointed out for weld metals. Besides these factors, it is well accepted that neutron irradiation can strongly modify SCC behavior by radiolysis of coolant water and microstructural/microchemical changes in materials produced by displacement damage. Although many studies have examined the effects of irradiation on SCC in the last few decades, most investigations have focused on the SCC behavior of post-irradiated materials. Since radiolysis can affect SCC behavior under irradiation, it is important to accumulate sufficient experimental data through in-situ irradiation SCC tests to improve our understanding of the effects of irradiation on SCC.

In the present study, an in-beam SCC testing machine was newly developed and installed in the beam-line of $17 \mathrm{MeV}$ protons at the NIMS cyclotron facility. Stress corrosion tests in pure water at $473 \mathrm{~K}$ were conducted for

*Corresponding author, E-mail: murase.yoshiharu@nims.go.jp
Table 1 Chemical compositions of SUS304 and SUS308 (mass\%).

\begin{tabular}{rrcccccccc}
\hline & $\mathrm{Ni}$ & $\mathrm{Cr}$ & $\mathrm{Mn}$ & $\mathrm{V}$ & $\mathrm{C}$ & $\mathrm{Si}$ & $\mathrm{P}$ & $\mathrm{S}$ & $\mathrm{Fe}$ \\
\hline 304 & 8.86 & 18.47 & 0.85 & 0.046 & 0.05 & 0.56 & 0.026 & 0.002 & balance \\
308 & 10.55 & 19.05 & 1.73 & 0.064 & 0.02 & 0.23 & 0.026 & 0.004 & balance \\
\hline
\end{tabular}

welded 308 stainless steel under proton irradiation. The objective was to investigate the in-beam effect on the formation of corrosion pits leading to the initiation of SCC at weld metal.

\section{Experimental Procedures}

\subsection{Specimen preparation}

The material used in the present study was a multi-layer welding of SUS304 with SUS308 wiring. The chemical compositions of SUS304 and SUS308 are shown in Table 1; details of the welding conditions were described elsewhere. ${ }^{9)}$ Figure 1 shows the processes of specimen preparation. The welded material was sliced and punchedout into a specimen shape with the fusion zone of the weld metal (SUS308) positioned at the specimen gauge as shown in Fig. 1(a). The dimensions of the specimen are shown in Fig. 1(b). The punched-out specimen was mechanically ground to a thickness of $0.14 \mathrm{~mm}$ and then polished to a mirror finish for the stress corrosion tests. In order to examine the metallic structure of the fusion zone at the specimen gauge, the specimen was chemically etched by aqua regia. A cast structure with the presence of ferrite phases in the austenite matrix was observed for the specimen, as shown in Fig. 1(c). The slicing of the welded material for specimen preparation was conducted until $8 \mathrm{~mm}$ depth form the welding surface. As a result of tensile tests at $473 \mathrm{~K}$ for the specimens processed from the same welded material, the tensile strength (TS) and $0.2 \%$ yield stress $(0.2 \%$ YS $)$ were $400 \pm 20$ and $320 \pm 20 \mathrm{MPa}$ on average with error range, respectively. 
(a)
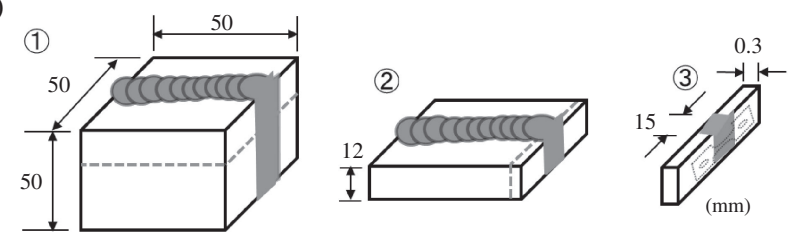

(b)

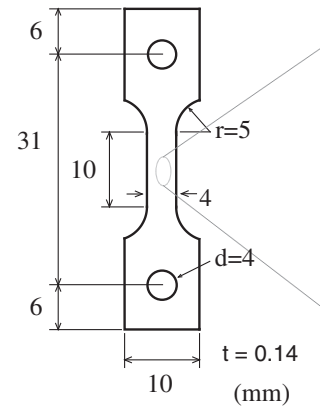

(c)

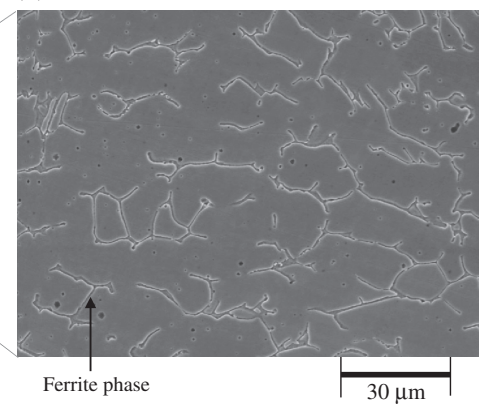

Fig. 1 Specimen preparation for SCC test; (a) Sampling of specimen from welded joint (b) Specimen dimensions for SCC test (c) Optical microscopic photo of metallic structure on fusion zone at specimen gauge.

\subsection{In-beam stress corrosion testing apparatus}

The in-beam stress corrosion testing apparatus developed in NIMS is schematically presented in Fig. 2. As shown in Fig. 2(a), a compact autoclave (material: SUS316, capacity: $180 \mathrm{~mL}$, flow rate: $0.17 \mathrm{~mL} / \mathrm{s}$, max. pressure: $2 \mathrm{MPa}$ ) was installed in the irradiation chamber connected to the beamline of the NIMS cyclotron; details of the beam-line and irradiation chamber were described elsewhere. ${ }^{10)}$ The specimen in the autoclave was not only stressed by a coiled spring loading system but also irradiated with highly energetic proton particles in a high-temperature, high-pressure environment $(473 \mathrm{~K}, 2 \mathrm{MPa})$. The loading system applies a constant tensile force on the specimen, ranging up to $50 \mathrm{~N}$. A system for monitoring the electrical corrosion potential (ECP) on the specimen was also installed in the autoclave. This system consists of a high-resistance electrometer (Hokuto Denko HA-151B) and an external pressure balanced reference electrode $(\mathrm{Ag} / \mathrm{AgCl} \quad(0.1 \mathrm{M} \mathrm{KCl}))$. The electrode was maintained at $300 \mathrm{~K}$ by a cooled water jacket. The temperature of feed water was monitored by the CA thermocouple in the autoclave. The temperature was controlled at $473 \mathrm{~K}$ during tests by adjusting the output of the autoclave heater and pre-heater. The specimen in the autoclave was irradiated

(a)

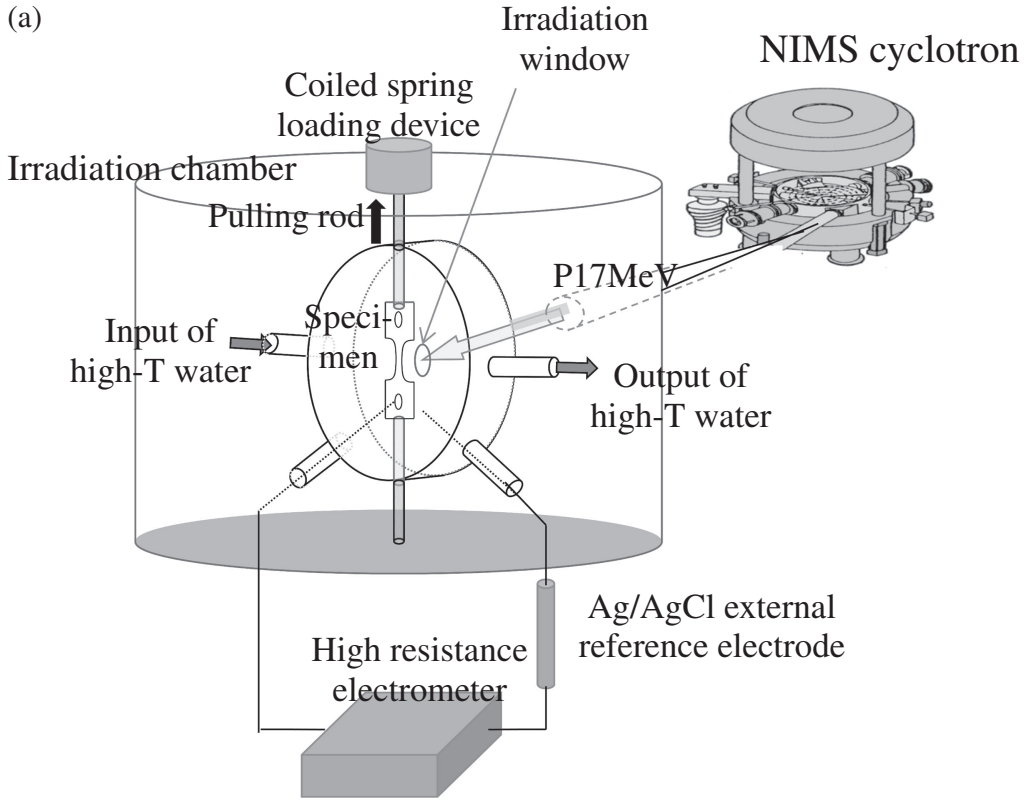

(b)

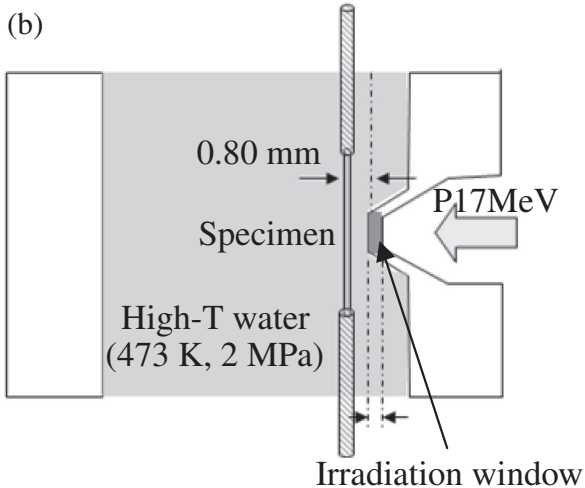

(c)

Ion exchanger

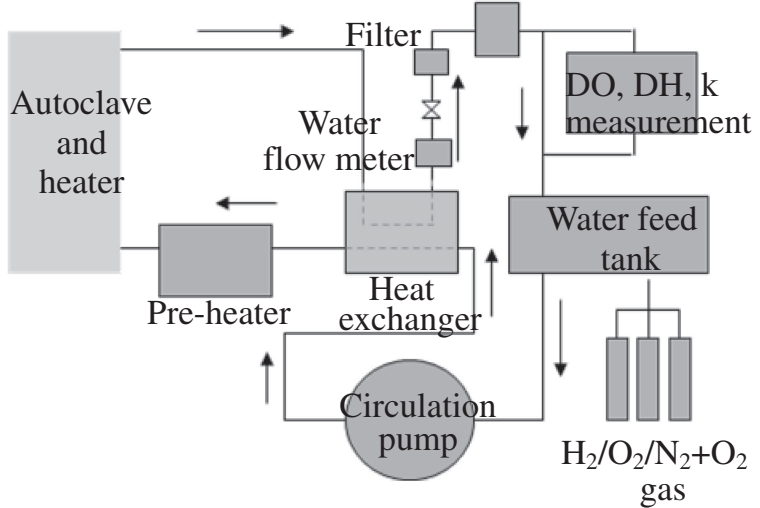

Fig. 2 Schematic figures of in-beam stress corrosion testing apparatus; (a) Installation of autoclave in irradiation chamber (b) Cross section of autoclave (c) Water circulation system. 


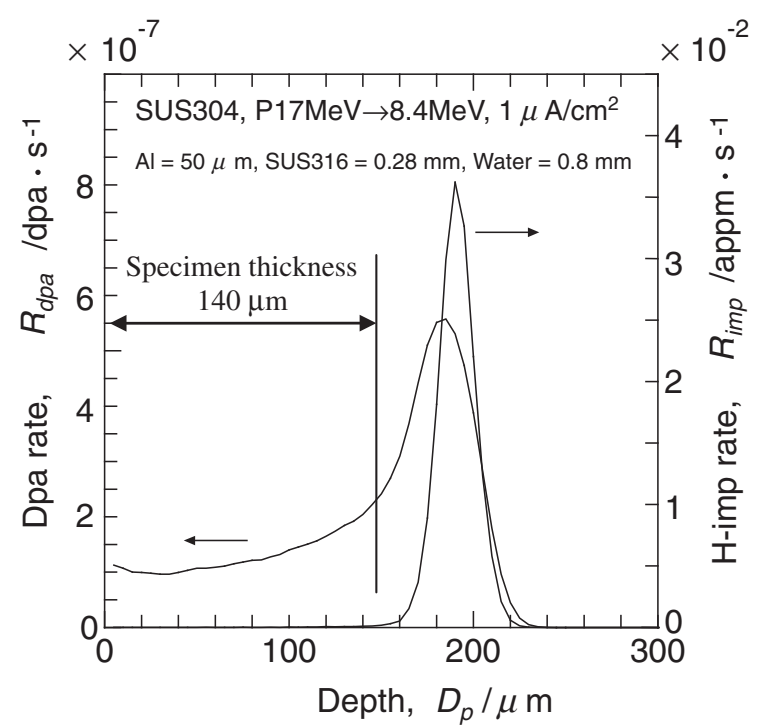

Fig. 3 Depth dependences of displacement damage rate and hydrogen implantation rate.

with highly energetic proton particles penetrating through the irradiation window (SUS316, $\Phi=5 \mathrm{~mm}$, thickness: 0.28 $\mathrm{mm}$ ), as shown in Fig. 2(b). The specimen was fixed at a distance of $0.8 \mathrm{~mm}$ from the irradiation window in order to avoid the influence of crevice corrosion. The water circulation system shown in Fig. 2(c) consists of a compact autoclave, high-pressure pump, heat exchanger, autoclave heater, pre-heater, ion exchanger, water feed tank and analytical branch loop for monitoring the concentration of dissolved oxygen (DO) and hydrogen (DH) as well as the conductivity $k$. The measurement ranges were from $0.1 \mathrm{ppb}$ to $20 \mathrm{ppm}$ for DO and $\mathrm{DH}$, and from 0.01 to $20 \mu \mathrm{S} / \mathrm{cm}$ for conductivity $k$. Data of DO, DH, $k$, temperature and ECP were sampled every $1 \mathrm{~s}$ and recorded by a data logger device (Graphtec GL220). Figure 3 shows the depth dependences of displacement damage rate and hydrogen implantation rate calculated by the SRIM2006 code for SUS308 in the present experiment. The energetic degradation of proton particles through the aluminum foil wall (chamber bulkhead), irradiation window and water was also calculated as from 17 to $8.4 \mathrm{MeV}$ at the irradiated surface of the specimen. As shown in Fig. 3, the specimen with a thickness of $0.14 \mathrm{~mm}$ ensures that the variation of displacement damage is within $\pm 30 \%$ between the two surfaces.

\subsection{Experimental conditions}

The in-beam stress corrosion tests were conducted at a low concentration of DO and DH at $473 \mathrm{~K}$ for $2.16 \times 10^{5} \mathrm{~s}$. The concentration of DO and $\mathrm{DH}$ was controlled to be below 5 and $10 \mathrm{ppb}$ during the tests, respectively. The loading stress on the specimen gauge was adjusted to 0 and $300 \mathrm{MPa}$. The beam intensity of protons was set to $1.0 \mu \mathrm{A} / \mathrm{cm}^{2}$, corresponding to the displacement damage rate of $1.3 \times 10^{-7}$ $\mathrm{dpa} / \mathrm{s}$ as well as hydrogen implantation of $5.9 \times 10^{-5}$ appm/s on average for the specimen. As control tests, offbeam tests were also conducted under the same conditions. ECP was measured for all the tests. After the stress corrosion tests, the surfaces of all specimens were examined by
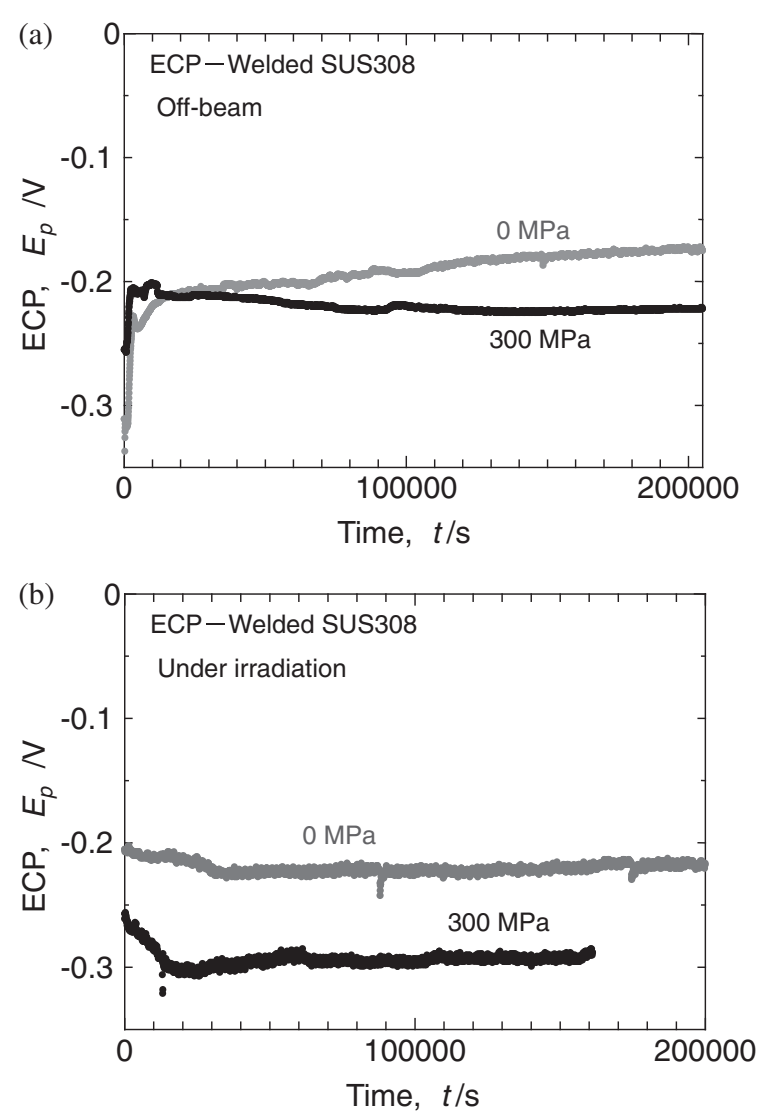

Fig. 4 Plots of ECP as a function of time for (a) off-beam and (b) in-beam corrosion tests.

a scanning electron microscope (SEM, JEOL5310). The density and size distribution of corrosion pits were measured in an area of $129.4 \times 96.2 \mu \mathrm{m}^{2}$ on the surface opposite to the irradiation window for all specimens.

\section{Results and Discussion}

Figure 4 shows the plots of ECP as a function of time for the off-beam and in-beam tests at 0 and $300 \mathrm{MPa}$. Sampling of ECP was unexpectedly interrupted at about $1.7 \times 10^{5} \mathrm{~s}$ for the in-beam test at $300 \mathrm{MPa}$ due to trouble with the data logger device. A gradual increase of ECP from -0.22 to $-0.17 \mathrm{~V}$ during the test was detected in the off-beam test at $0 \mathrm{MPa}$, while a slight decrease from -0.20 to $-0.22 \mathrm{~V}$ was detected in the off-beam test at $300 \mathrm{MPa}$, as shown in Fig. 4(a). As for the in-beam tests shown in Fig. 4(b), plots of ECP shifted from -0.20 to $-0.22 \mathrm{~V}$ and then stayed at $-0.22 \mathrm{~V}$ for the test at $0 \mathrm{MPa}$, while the plots sharply decreased from -0.25 to $-0.30 \mathrm{~V}$ and then remained stable at $-0.28 \mathrm{~V}$ for the tests at $300 \mathrm{MPa}$. Typical specimen surfaces after the stress corrosion tests are displayed in Fig. 5 for the off-beam specimens at (a) $0 \mathrm{MPa}$ and (b) $300 \mathrm{MPa}$, and for the in-beam specimens at (c) $0 \mathrm{MPa}$ and (d) $300 \mathrm{MPa}$. The formation of corrosion pits on the surface was detected in all specimens. Most of the corrosion pits appeared to have formed at the boundaries of ferrite phases in the austenite matrix. As shown in Fig. 5(d), the initiation of surface cracking followed by coalescence of numerous larger corrosion pits at the boundaries of ferrite phases was 
(a)

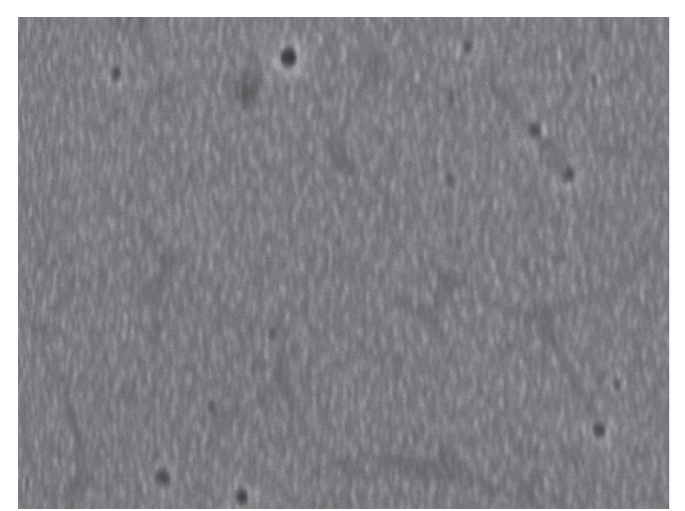

(c)

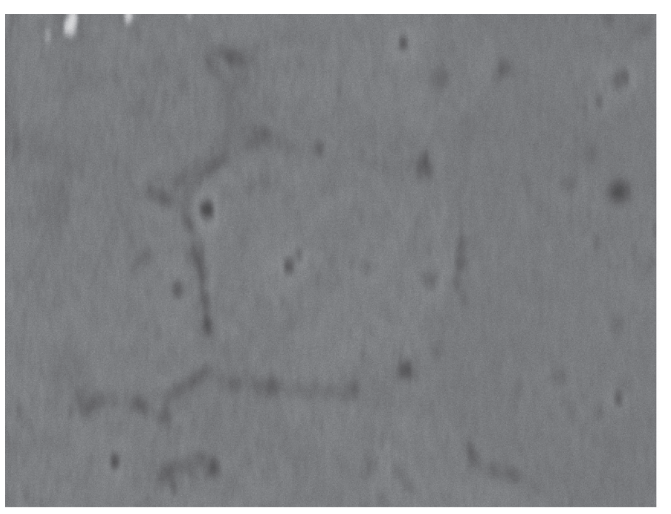

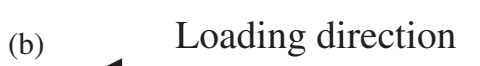

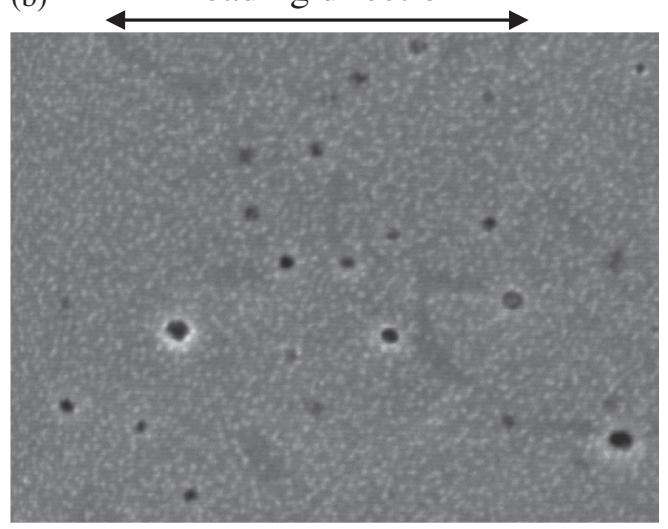

(d)

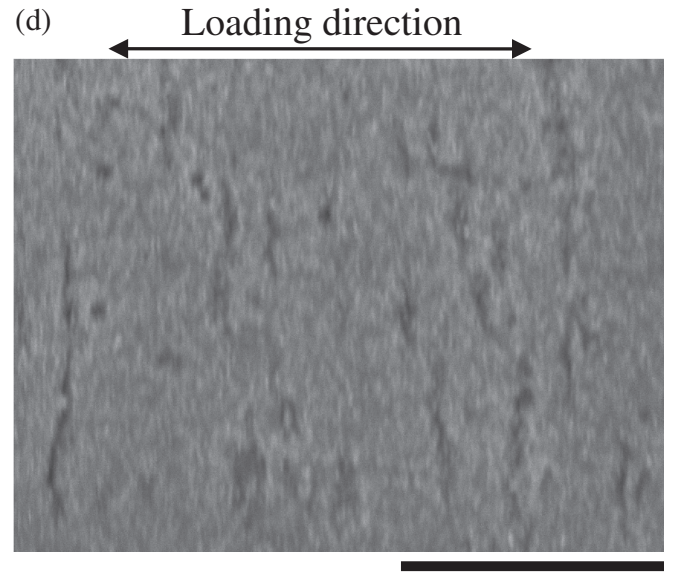

$10 \mu \mathrm{m}$

Fig. 5 SEM photos of surface oxide layer for the off-beam specimens at (a) $0 \mathrm{MPa}$ and (b) $300 \mathrm{MPa}$, for the in-beam specimens at (c) $0 \mathrm{MPa}$ and (d) $300 \mathrm{MPa}$.

observed for the in-beam specimen at $300 \mathrm{MPa}$. The density and size distribution of corrosion pits are presented in Fig. 6 for the off-beam specimens at (a) $0 \mathrm{MPa}$ and (b) $300 \mathrm{MPa}$, and for the in-beam specimens at (c) $0 \mathrm{MPa}$ and (d) $300 \mathrm{MPa}$. Due to the resolution of SEM analyses, corrosion pits with a diameter of $0.2 \mu \mathrm{m}$ or over were taken into account for the measurements. In comparison with the result of the off-beam specimen at $0 \mathrm{MPa}$, the formation and growth of corrosion pits seemed to be promoted in either the loading or in-beam conditions. A less substantial increase of the density for the in-beam specimen at $300 \mathrm{MPa}$ was attributed to the coalescence of numerous larger corrosion pits.

It is well known that corrosion pits are preferentially formed at the boundaries of ferrite phases in the austenitic matrix at weld metals. Since the ferrite phase has a higher content of chromium than the matrix, the weakening of the passive film due to the depletion of chromium at the boundaries of ferrite phases has been documented in terms of the decrease in the resistance to pitting corrosion. ${ }^{5)}$ Furthermore, it has been pointed out that the lattice mismatch at the boundary induces localized disturbance of the passive film. $\left.{ }^{6}\right)$ Higher susceptibility to the initiation of cracking along the boundaries under stress corrosion tests has been reported in some literatures. ${ }^{7,8)}$ Electrochemical monitoring is well recognized as a useful way to estimate the state of the passive film on a specimen surface. Because the electrochemical potential reflects the activation of electrochemical reactions, the inactivation of reactions due to the growth of passive film is perceived by the increase of ECP. In the present study, the gradual increase of ECP in the off-beam test at $0 \mathrm{MPa}$ (see Fig. 4(a)) implied the formation of a passive film on the specimen surface. However, in the off-beam test at $300 \mathrm{MPa}$, the slight decrease of ECP (see Fig. 4(a)) as well as the enhanced formation and growth of corrosion pits (see Fig. 6(b)) would be ascribed to the additional electrochemical reactions at the stress induced micro-defects in the passive film weakened at the boundaries of ferrite phases. As for the in-beam tests, it is plausible that radiolysis products such as hydroperoxy and other radical species formed during proton irradiation would modify the behavior of SCC. Some researchers ${ }^{11,12)}$ have examined the electrochemical behavior of stainless steels during proton irradiation, and demonstrated the promotion of electrochemical reactions induced by radiolysis products at the interface of the steels. A decrease of electrochemical potential followed by slow recovery in a transient period during proton irradiation has been correlated with the enhanced reaction followed by growth of passive film at the interface. ${ }^{11)}$ This decrease of electrochemical potential during irradiation was similar to the present results of the ECP plots for the in-beam tests shown in Fig. 4(b), although the recovery of ECP was not clearly detected. Electrochemical reactions on passive film with radiolysis 
(a)

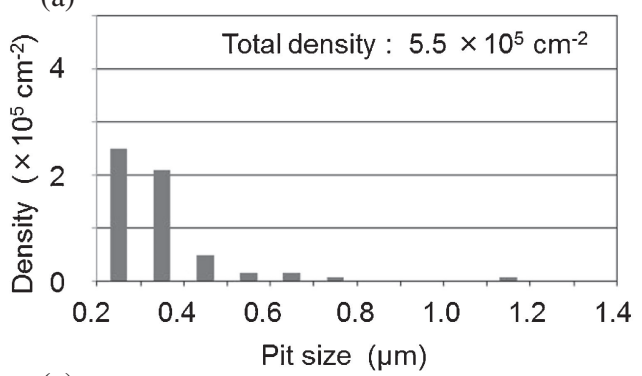

(c)

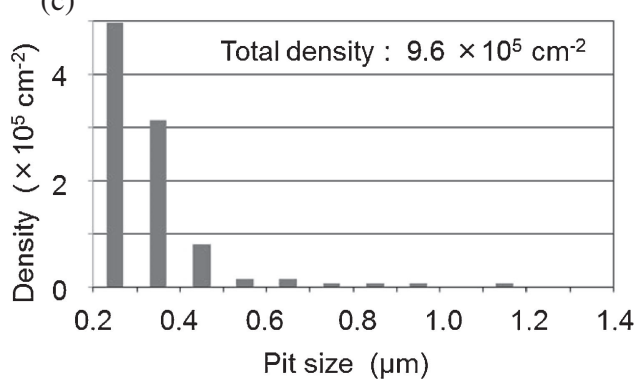

(b)

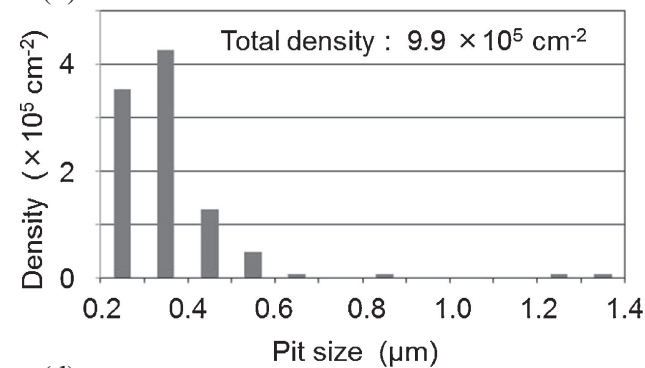

(d)

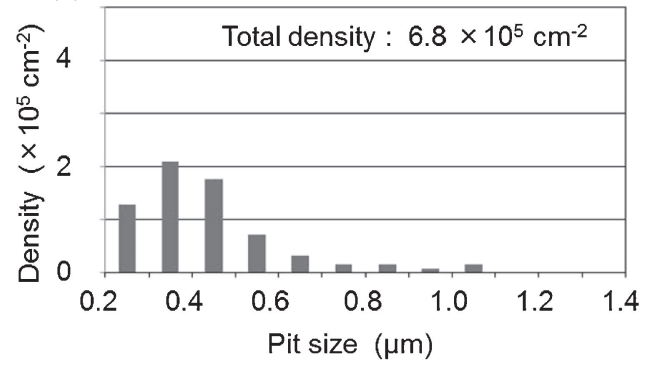

Fig. 6 Density and size distribution of corrosion pits for the off-beam specimens at (a) $0 \mathrm{MPa}$ and (b) $300 \mathrm{MPa}$, for the in-beam specimens at (c) $0 \mathrm{MPa}$ and (d) $300 \mathrm{MPa}$.

products during proton irradiation would enhance the formation and growth of corrosion pits in the in-beam tests at $0 \mathrm{MPa}$, as shown in Fig. 6(c), leading to the suspended recovery of ECP (see Fig. 4(b)). The present results involved the simultaneous effects of loading and irradiation for the inbeam tests at $300 \mathrm{MPa}$. Extensive electrochemical reactions at the stress-induced defects in the passive film with radiolysis products would be responsible for not only the lower stable ECP but also the initiation of surface cracking followed by coalescence of numerous larger corrosion pits at the boundaries of ferrite phases (see Fig. 5(d)). Although the surface cracks observed in the present experiment were too small to be ascertained as developing into main cracks, it is noted that the initial process of SCC at weld metal would be accelerated under irradiation.

The present study is the first report of experimental results obtained by using the in-beam stress corrosion testing apparatus. In the first step of a series of in-beam SCC tests, pure water was selected as the solution environment in order to minimize the effects of solute elements on SCC behavior. In the present condition with concentration of DO of less than $5 \mathrm{ppb}$, insufficient growth of passive film may contribute to the formation of corrosion pits even in the off-beam tests at $0 \mathrm{MPa}$. With respect to the radiolysis products during irradiation, the disappearance of the products through reactions with hydrogen has been reported in water containing DH. ${ }^{13)}$ Therefore, more extensive studies with various concentrations of DO and $\mathrm{DH}$ are needed to clarify the in-beam effects on SCC behavior.

\section{Conclusions}

Stress corrosion tests in pure water at $473 \mathrm{~K}$ were performed for welded 308 stainless steel under proton irradiation. The specimens used for the SCC tests had a cast structure with the presence of ferrite phases in the austenite matrix. From the experimental results of in-beam and offbeam tests at 0 and $300 \mathrm{MPa}$, the following conclusions were drawn:

(1) A gradual increase of electrochemical corrosion potential (ECP) was detected in the off-beam test at $0 \mathrm{MPa}$, while a slight decrease of ECP was detected in that at $300 \mathrm{MPa}$. As for the in-beam tests, ECP slightly decreased and then remained stable in the test at $0 \mathrm{MPa}$, but sharply decreased and then remained stable in the test at $300 \mathrm{MPa}$.

(2) The formation of corrosion pits on the surface was detected in all specimens. Most of the corrosion pits appeared to have formed at the boundaries of ferrite phases in the austenite matrix. The formation and growth of corrosion pits seemed to be promoted in either the loading or in-beam condition. The initiation of surface cracking followed by coalescence of numerous larger corrosion pits was observed for the in-beam specimens at $300 \mathrm{MPa}$.

(3) Extensive electrochemical reactions at the stressinduced defects in passive film with radiolysis products would be responsible for not only the lower stable ECP but also the initiation of surface cracking for the inbeam specimen at $300 \mathrm{MPa}$. The initial process of SCC at weld metal would be accelerated under irradiation.

\section{Acknowledgement}

The authors wish to thank Dr. Hiromichi Hongo, NIMS, for providing the welded materials and technical support for specimen preparation.

\section{REFERENCES}

1) Z. Fang, Y. Wu and R. Zhu: Corrosion 50 (1994) 171-175.

2) T. M. Devine and B. J. Drummond: Corrosion 37 (1981) 104-115. 
3) I. Hamada and K. Yamauchi: Metall. Mater. Trans. A 33 (2002) 29072919.

4) H. Shaikh, H. S. Khatak, S. K. Seshadri, J. B. Gnanamoorthy and P. Rodriguez: Metall. Mater. Trans. A 26 (1995) 1859-1868.

5) K. S. Raja and K. P. Rao: Corros. Sci. 51 (1995) 586-592.

6) G. M. Reddy, K. S. Rao and T. Sekhar: Sci. Tech. Weld. Join. 13 (2008) 363-377.

7) B. T. Lu, Z. K. Chen, J. L. Luo, B. M. Patchett and Z. H. Xu: Electrochimica Acta 50 (2005) 1391-1403.

8) Z. Lu, T. Shoji, Y. Takeda, Y. Ito, A. Kai and N. Tsuchiya: Corros. Sci.
50 (2008) 625-638.

9) M. Yamazaki, Y. Monma, H. Hongo, T. Watanabe, J. Kinugawa and Y. Muramatsu: Trans. NRIM 33 No. 1 (1991) 64-71.

10) Y. Murase, J. Nagakawa, N. Yamamoto and Y. Fukuzawa: ASTM STP 1366, (ASTM, West Conshohocken, 2000) pp. 713-724.

11) B. Muzeau, S. Perrin, C. Corbel, D. Simon and D. Feron: J. Nucl. Mater. 419 (2011) 241-247.

12) E. Leoni, C. Corbel, V. Cobut, D. Simon, D. Feron, M. Roy and O. Raquet: Electrochem. Acta 53 (2007) 495-510

13) K. Fukuya: J. Nucl. Sci. Technol. 50 (2013) 213-254. 